\title{
Tranquilidad del alma y poesía en De rerum natura
}

\author{
Óscar Martiarena
}

A

1 inicio de la conocida carta que dirige a su discípulo Heródoto, conservada gracias a Diógenes Laercio, dice Epicuro que se ha abocado a la preparación de un compendio de su doctrina, contenido en la propia carta, a fin de que quienes no puedan estudiar cada una de sus obras, ni siquiera las más importantes, tengan presentes sus principios fundamentales y, en su oportunidad, sean capaces de prestarse ayuda a sí mismos al acogerse a la teoría de la naturaleza. ${ }^{1}$ Pero además, Epicuro añade que el compendio, al proporcionar una comprensión del conjunto de su pensamiento, habrá de ser útil también a quienes hayan avanzado ya en su estudio, dado que el tener a la vista el todo les facilitará expresar sus conocimientos a través de reglas y máximas elementales y, con ello, contarán con la posibilidad de una eficaz y rápida utilización de la teoría de la naturaleza (physiologia), con cuya práctica se alcanza, advierte, una vida tranquila. ${ }^{2}$

Antes de iniciar la exposición de los contenidos de su teoría de la naturaleza, Epicuro presenta dos principios esenciales de su pensamiento. El primero se refiere a la importancia de expresar con claridad el significado de las palabras, lo que a su vez permite la emisión de juicios precisos en la investigación, en las opiniones e incluso en las dudas, y, con respecto al segundo, Epicuro recuerda a sus discípulos la obligación que, en el ámbito de su doctrina, tiene el estar atentos a las sensaciones, a las percepciones y a los sentimientos experimen-

${ }^{1}$ Epicuro, "Carta a Heródoto", en Diogène Laërce, Vies et doctrines des philosophes illustres. 10a. ed. Le livre de poche, Librairie Général Française, 1999, (35), pp. 1 264-1 265. Los números entre paréntesis que aparecen en las citas de las obras de Epicuro refieren a los fragmentos correspondientes al libro x de la obra de Diógenes Laercio.

${ }^{2}$ Ibid., (36-37), pp. 1 265-1 266. 
tados, todo lo cual ha de permitir hacer manifiesto lo que queremos confirmar o lo que no nos es evidente. ${ }^{3}$

Habiendo enunciado ambos principios, Epicuro emprende la descripción de su teoría de la naturaleza. Apunta así que nada nace de la nada, que el universo es infinito y está compuesto únicamente de cuerpos y de vacío, ambos también infinitos. Asegura que, en su infinitud, el todo ha sido siempre tal y como es ahora y que entre los cuerpos unos son compuestos y otros simples, los llamados átomos, los cuales son indivisibles e inmutables, y agrega que es a partir de éstos últimos que se constituyen los primeros. ${ }^{4}$ De los átomos eternos, es decir, indestructibles e inmutables, Epicuro afirma que el número de sus formas está definido, que el de aquellos que tienen la misma hechura es infinito, que se encuentran en perpetuo movimiento, que chocan continuamente y por su dureza rebotan hasta que al entrelazarse se combinan formando así los mundos existentes, los cuales, para Epicuro, también pueden ser infinitos. ${ }^{5}$ A su vez, sostiene que de los cuerpos sólidos y con su misma forma, aunque sumamente ligeras, se desprenden imágenes, emanaciones continuas, réplicas de los objetos que reproducen su forma. A tales imágenes, Epicuro las llama éidola, cuya velocidad de desplazamiento depende de los obstáculos a los que enfrentan (principio al que, dada su utilidad, Epicuro sugiere conservar en la memoria), y añade que por medio de ellas percibimos, no sólo la forma de los objetos sino que incluso pensamos. ${ }^{6}$ De modo que, dado que gracias a las emanaciones procedentes de los objetos exteriores que se introducen en nosotros pensamos, Epicuro sostiene que el error o el engaño a los que estamos expuestos en el conocimiento de la naturaleza se origina, no por la acción de los sentidos, sino por lo que nuestra opinión añade a lo percibido, la cual tiene origen en nuestra capacidad de discernir. ${ }^{7}$ Por ello, a fin de no confundir la verdad con el error, Epicuro sugiere que, en el momento en el que conocemos los diversos objetos, no olvidemos las fuerzas que actúan dentro de nosotros mismos. ${ }^{8}$

Después de apuntar que la fuente de los errores con respecto a nuestro juicio, más que en los sentidos descansa en nuestro discernimiento, Epicuro se detiene en el oído y en el olfato, en la forma en la que son afectados por las emanaciones provenientes de los objetos, ${ }^{9} \mathrm{y}$ presenta algunos elementos más de su teoría atómica. Así, asegura que los átomos están formados por

\footnotetext{
${ }^{3}$ Ibid., (38), p. 1266.

${ }^{4}$ Ibid., (39-41), pp. 1 267-1 269.

5 Ibid., (42-45), pp. 1 269-1 270.

${ }^{6}$ Ibid., (46-49), pp. 1 271-1 272.

${ }^{7}$ Ibid., (50-51), pp. 1 273-1 274.

${ }^{8}$ Ibid., (52), p. 1274.

${ }^{9}$ Ibid., (52-53), pp. 1 274-1 275.
} 
partes más pequeñas, aunque indiscernibles, y que en el vacío, la velocidad del movimiento de los átomos, cualquiera sea su forma, es siempre la misma, la cual varía cuando se topan con obstáculos o cuando forman parte de un cuerpo. ${ }^{10}$

Por otra parte, es de importancia señalar que, para Epicuro, al predicado de la existencia del vacío sólo llegamos a partir de la mente, ${ }^{11}$ y que los periodos de tiempo son concebibles sólo mediante el uso de la razón; ${ }^{12}$ es decir, vacío y tiempo son, para Epicuro, conceptos que la mente produce, dado que en sí mismos no son percibidos por los sentidos. De manera que si a la capacidad de formular conceptos añadimos la de discernir ya mencionada, tenemos que Epicuro otorga a la mente, es decir, al alma, una actividad fundamental en su teoría de la naturaleza.

Ahora bien, dado que sostiene que en el todo sólo existen cuerpos y vacío, es natural que al tratar de las sensaciones y los sentimientos, Epicuro se refiera al alma en términos corporales. Así, la describe como un cuerpo sutil disperso por todo el organismo, formado por una mezcla de aire y calor, aunque añade que una de sus partes está constituida por partículas singulares que hacen posibles las facultades que la caracterizan, como el sentir y el pensar. ${ }^{13}$ Pero dado que dichas facultades las perdemos con la muerte, Epicuro afirma que, separado del alma, el cuerpo no experimenta sensación alguna, ${ }^{14}$ y que destruido el cuerpo, el alma se dispersa y pierde la capacidad de experimentar sensaciones. ${ }^{15}$ A su vez, dado que dentro de su teoría de la naturaleza considera que lo único incorpóreo que existe es el vacío, Epicuro sostiene que yerran quienes afirman que el alma es incorpórea, puesto que en caso de que no fuese corporal, no sería capaz de realizar ni sufrir nada, siendo que es claro que el alma cuenta con ambas características. ${ }^{16}$

En relación con los movimientos de los cuerpos celestes, así como con sus órbitas, sobre los eclipses y fenómenos similares, Epicuro sostiene que no se originan por obra de ser alguno que los gobierne, es decir, que no descansan en la mano de divinidad alguna, la cual, por naturaleza, continúa, goza de completa felicidad e inmortalidad, y está exenta de preocupaciones, iras y temores que, asegura, tienen su origen en la debilidad de los seres humanos. ${ }^{17}$ Asimismo, firma que los movimientos de los astros se producen de acuerdo con la manera

${ }^{10}$ Ibid., (58-62), pp. 1 277-1 279.

${ }^{11}$ Ibid., (40), p. 1268.

${ }^{12}$ Ibid., (62), p. 1279.

${ }^{13}$ Ibid., (63), pp. 1 279-1 280.

${ }^{14}$ Ibid., (64), p. 1280.

${ }^{15}$ Ibid., (65), pp. 1 280-1 281.

${ }^{16}$ Ibid., (67), p. 1281.

${ }^{17}$ Ibid., (76-77), p. 1 286-7. 
en la que, después de múltiples colisiones, los átomos se agruparon y que tal conocimiento nos proporciona felicidad, en tanto nos permite conocer a la naturaleza y comprender las leyes supremas. ${ }^{18}$ Además, si bien reconoce que son posibles diversas explicaciones sobre el movimiento de los cuerpos celestes, lo importante es, sugiere, tener presente que una gran turbación se produce en el alma de quienes consideran que una misma naturaleza puede ser feliz e inmortal, al tiempo de experimentar deseos; a lo que añade que sufren quienes, por su creencia en los mitos, temen un tormento eterno o incluso la muerte misma. Somos presas de tales aflicciones, asegura, por un estado irracional del alma motivado por creencias insensatas. ${ }^{19}$ Así, Epicuro apunta: "La tranquilidad del alma (ataraxia) nace de liberarse de todos estos temores y de rememorar de forma continua los principios generales y los preceptos fundamentales". ${ }^{20}$ De modo que, continua, lo que conviene es atenernos a las sensaciones, a las comunes y a las particulares, que constituyen la evidencia inmediata para nuestro conocimiento. Al aplicarnos a ello, descubriremos de manera correcta la fuente de donde provienen la perturbación y el miedo, de los cuales podemos liberarnos al investigar las causas verdaderas de los fenómenos celestes y de lo que sucede a menudo y provoca gran temor al resto de los hombres. ${ }^{21}$

En la carta a Pitocles encontramos algunos elementos más de la teoría epicúrea de la naturaleza. Como la dirigida a Heródoto, se trata de un compendio, conservado también gracias a Diógenes Laercio, en la que Epicuro se ocupa de la explicación de los fenómenos celestes, no sin antes recordar que la finalidad de tal conocimiento es alcanzar la tranquilidad del alma y una sólida confianza, las cuales son el fin, advierte, de cualquier investigación. ${ }^{22}$ A su vez, como en la carta a Heródoto, Epicuro sostiene que, con respecto a los fenómenos celestes, habría que asumir que no existe una única explicación de su naturaleza, aunque confía en que obtendremos la máxima serenidad al acudir al método de las múltiples explicaciones basadas en los fenómenos y al admitir las que tengan mayor pertinencia. ${ }^{23}$ A continuación, Epicuro se refiere a los astros y, en particular, a la formación del Sol y de la Luna y a la forma en que aparecen y se ocultan periódicamente, a cuyo respecto afirma que en manera alguna habremos de considerar como causa de sus movimientos regulares a los dioses, e incluso afirma que si adoptamos una posición opuesta a la evidencia de los hechos, nunca alcanzaremos la verdadera serenidad. ${ }^{24}$

${ }^{18}$ Ibid., (77-79), p. 1287.

${ }^{19}$ Ibid., (80-81), pp. 1 288-1 289.

${ }^{20}$ Ibid., (82), p. 1289.

${ }^{21}$ Ibid., (82), pp. 1 289-1 290.

${ }^{22}$ Epicuro, "Carta a Pitocles", en Diogène Laërce, op. cit., (85), pp. 1 290-1 291.

${ }^{23}$ Ibid., (86-87), pp. 1 291-1 292.

${ }^{24}$ Ibid., (96), p. 1295. 
Además de referirse a los astros, Epicuro alude a la formación de las nubes y la lluvia, los truenos y los relámpagos, los rayos, los terremotos, los vientos, el granizo, la nieve, el rocío, la escarcha, el hielo, el arco iris, el halo de la luna, los cometas, las estrellas fugaces. Y en todo ello, claro está, Epicuro presenta explicaciones congruentes con su teoría de la naturaleza, con las que busca dejar de lado los mitos a los que considera, como ya mencionamos, fuente de turbación y temor. De hecho, al final de la carta, Epicuro recuerda a Pitocles que sólo con la teoría de la naturaleza podrá superar los errores contenidos en los mitos. ${ }^{25}$

Como sabemos, la carta a Meneceo, contenida también en el tratado de Diógenes Laercio, inicia con una sentencia fundamental del pensamiento epicúreo: "Nadie por ser joven vacile en filosofar ni por hallarse viejo de filosofar se canse. Porque para alcanzar la salud del alma, nunca se es ni demasiado viejo ni demasiado joven". ${ }^{26}$ Epicuro acompaña tal afirmación con una más: "practique la filosofía tanto el joven como el viejo", el primero para mantenerse joven y el segundo para que pueda ser joven y viejo a la vez, y mantener la serenidad ante el futuro. ${ }^{27}$ Ambas, claro está, son máximas, dice Epicuro a Meneceo, necesarias para alcanzar una vida feliz, y a continuación añade algunas observaciones más: es necesario considerar a la divinidad, afirma, como un ser incorruptible, dichoso y, por tanto, inmortal; los impíos, agrega, no son los que reniegan de los dioses, sino aquellos que les atribuyen las opiniones de la multitud; los bienes y los males, concluye, no nos llegan de los dioses, puesto que ellos, ocupados sólo en sus virtudes, consideran extraño a todo aquel que no sea su semejante. ${ }^{28}$ A su vez, Epicuro alienta a Meneceo a pensar que la muerte es nada para los seres humanos, dado que todo bien y todo mal residen en la sensación, cuya ausencia caracteriza a la muerte: "El peor de los males, la muerte, no significa nada para nosotros, porque mientras vivimos no existe y cuando está presente nosotros no existimos". ${ }^{29}$

Con respecto a los deseos, Epicuro sostiene que unos son necesarios y otros vanos, y que entre los primeros, unos son indispensables para obtener la felicidad, otros para el bienestar y otros para la vida en general. ${ }^{30}$ Conocer los deseos, añade, nos permite elegir aquellos que nos conducen a alcanzar una vida feliz y, por tanto, la tranquilidad del alma. No por ello, sabemos, Epicuro condena el placer, al que entiende como ausencia de dolor y como principio de una vida feliz. Pero porque el placer es el bien primero, Epicuro sugiere no ha-

${ }^{25}$ Ibid., (116), p. 1304.

${ }^{26}$ Epicuro, "Carta a Meneceo", en Diogène Laërce, op. cit., (122), p. 1308.

${ }^{27}$ Ibid., (122), p. 1308.

${ }^{28}$ Ibid., (123), p. 1308.

${ }^{29}$ Ibid., (125), p. 1309.

${ }^{30}$ Ibid., (127), p. 1310. 
cer uso indiscriminado de los placeres sino renunciar a muchos, en particular cuando del goce se sigue un trastorno mayor. Con frecuencia, subraya, muchos dolores son preferibles a los placeres, si a los dolores les sigue un placer superior. Así, aconseja a Meneceo un cálculo entre los beneficios e inconvenientes de los placeres, dirigido a favorecer la autarquía y la autosuficiencia. ${ }^{31} \mathrm{~A}$ la par, sugiere a su discípulo alimentos frugales y placeres simples y, sobre todo, el bien superior: un buen juicio (phrónesis), del cual provienen, señala, todas las virtudes y nos proporciona una vida feliz, sensata y bella. ${ }^{32}$ Claro está, una vida en la que se goza de la tranquilidad del alma.

Si con los textos conservados de Epicuro nos acercamos al fascinante y prodigioso poema de Tito Caro Lucrecio, escrito en latín a mediados del siglo I a. C. y titulado De rerum natura, podemos constatar que los contenidos a los que hemos aludido, están presentes a lo largo de los poco más de 7400 hexámetros que constituyen los seis libros del poema. ${ }^{33}$

Ahora bien, es probable que, para la composición de De rerum natura, Lucrecio haya conocido otros textos de Epicuro que, a lo largo de los siglos, se perdieron, dada la censura de la que fueron objeto durante la Antigüedad tardía y la Edad Media. Pero si bien es cierto que muchos de los textos de Epicuro desaparecieron a lo largo del tiempo, también lo es el que los conservados por Diógenes Laercio, cuyos momentos fundamentales hemos querido subrayar, nos dan una idea general de la teoría con la que Lucrecio trabajó detenida y pródigamente la composición de su poema.

En efecto, todos los contenidos de las cartas a Heródoto, Pitocles y Meneceo están presentes en el poema de Lucrecio. De hecho, De rerum natura cumple con el objetivo general que Epicuro se propone al escribir la carta a

${ }^{31}$ Ibid., (129), p. 1311.

32 Ibid., (132), p. 1312.

${ }^{33}$ Existen varias versiones en castellano de De rerum natura. En primer lugar habría que mencionar la realizada por el Abad Marchena a fines del siglo XVIII y que tiene varias ediciones, entre ellas la de Editorial Porrúa que lleva el título de De la naturaleza. Entre las más cercanas a nosotros destacan: Tito Lucrecio Caro, De la naturaleza de las cosas, 2 vols. Versión de René Acuña. México, UNAM, 1963. (Bibliotheca scriptorum graecorum et romanorum mexicana). Lucrecio, De la natura de las cosas. Versión de Rubén Bonifaz Nuño. México, UNAM, 1984. (Bibliotheca scriptorum graecorum et romanorum mexicana). Lucrecio, De la realidad. Versión de Agustín García Calvo. Zamora, España, Lucina, 1997. Lucrecio, La naturaleza. Versión de Francisco Socas. Madrid, Gredos, 2003. Lucrecio, La naturaleza de las cosas. Versión de Miguel Castillo Bejarano. Madrid, Alianza, 2003. 
Heródoto, consistente en presentar en un sólo texto el conjunto de su doctrina, siempre con vistas a que su estudio y práctica sean una vía para alcanzar la tranquilidad del alma. De modo que, a lo largo de los seis libros del poema, Lucrecio desarrolla, a menudo ampliamente, la teoría epicúrea de la naturaleza sin olvidar ninguno de sus elementos fundamentales. Así, apunta que nada nace de la nada; ${ }^{34}$ que el universo es infinito; ${ }^{35}$ que son infinitos también los cuerpos y el vacío que lo constituyen; ${ }^{36}$ que los cuerpos pueden ser simples y compuestos, ${ }^{37}$ que los simples, es decir, los átomos, a los que Lucrecio llama cuerpos primeros,${ }^{38}$ son indivisibles e inmutables, ${ }^{39}$ los cuales, al combinarse, generan los compuestos; ${ }^{40}$ que el número de las formas de los átomos es limitado, mientras que el de los átomos de cada forma es infinito; ${ }^{41}$ que los átomos se encuentran en perpetuo movimiento y choque, ${ }^{42}$ hasta que llegan a formar los mundos existentes; ${ }^{43}$ que de los cuerpos se desprenden imágenes, sutiles emanaciones que replican sus formas, a las que Lucrecio llama simulacros, con los que, mediante los sentidos, ${ }^{44}$ percibimos los objetos y pensamos. ${ }^{45} \mathrm{~A}$ su vez, al tiempo de mostrar que el vacío ${ }^{46}$ y el tiempo ${ }^{47}$ son conceptos a los que llegamos a través de la mente, Lucrecio presenta una minuciosa descripción de la naturaleza del alma, ${ }^{48}$ sutil complejo de átomos dispuesto a lo largo de todo el cuerpo, ${ }^{49}$ donde el ánimo, es decir, la mente, lugar en el que descansa el "gobierno de la vida", es sólo una parte constitutiva, aunque fundamental, del alma, ${ }^{50}$ la cual, en su totalidad, a la par del cuerpo, es mortal. ${ }^{51}$

A su vez, siguiendo a Epicuro, Lucrecio se detiene en los cuerpos celestes, cuyos movimientos describe ajenos a los dioses, quienes, lejos del mundo, gozan de total felicidad y, en tanto inmortales, nada necesitan de nosotros, y ni

${ }^{34}$ Tito Lucrecio Caro, De rerum natura, libro I, 146-214.

${ }^{35}$ Ibid., libro I, 951-1 001.

${ }^{36}$ Ibid., libro I, 1 002-1 051.

${ }^{37}$ Ibid., libro I, 483-484.

${ }^{38}$ Ibid., libro I, 265-328,

${ }^{39}$ Ibid., libro I, 483-598.

${ }^{40}$ Ibid., libro II, 581-660.

${ }^{41}$ Ibid., libro II, 478-568.

42 Ibid., libro II, 80-141.

43 Ibid., libro I, 1 021-1 037.

${ }^{44}$ Ibid., libro IV, 26-705.

45 Ibid., libro IV, 722-822.

46 Ibid., libro I, 329-369.

${ }^{47}$ Ibid., libro I, 459-464.

48 Ibid., libro III, 94-416.

${ }^{49}$ Ibid., libro III, 177-230.

${ }^{50}$ Ibid., libro III, 136-176.

${ }^{51}$ Ibid., libro III, 417-829. 
el dolor ni la ira los toca. ${ }^{52}$ Es decir, de la mano de su maestro, Lucrecio sostiene que el universo carece de naturaleza divina, que los dioses son ajenos a su creación y, por tanto, que carece de sentido el que, a partir de los mitos, supongamos un castigo después de la muerte o penas eternas. ${ }^{53}$ Sugiere, en cambio, investigar el origen de temores y supersticiones, a fin de, a través de la contemplación y el conocimiento de la naturaleza, alejarlos de nosotros y alcanzar la tranquilidad del alma. ${ }^{54}$ De manera que, con tal finalidad, Lucrecio emprende la descripción de los cuerpos celestes, de la formación, el curso y el calor del Sol, de las fases de la Luna, de las causas de los eclipses, ${ }^{55}$ y de diversos fenómenos naturales como el trueno, el relámpago, el rayo, la lluvia, los terremotos, los volcanes, el magnetismo e incluso las epidemias. ${ }^{56}$

En fin, tal como en la carta a Meneceo, Lucrecio insta al lector a la práctica permanente de la filosofía, ${ }^{57}$ que nos lleva al conocimiento de la naturaleza inmortal y feliz de los dioses, siempre ajenos al mundo; ${ }^{58}$ a la consideración de que la muerte no significa nada para nosotros; ${ }^{59}$ al reconocimiento de que muchos de nuestros deseos son vanos y, con ello, origen de dolor y desdicha; ${ }^{60}$ que no hay razón para adherirse a la vida o temer a la muerte; ${ }^{61}$ y que la renuncia a algunos de nuestros deseos, acaso los más persistentes, conduce a un placer superior: la tranquilidad del alma. ${ }^{62}$

\section{III}

La presencia en el poema de cada uno de los principios contenidos en las cartas a Heródoto, Pitocles y Meneceo, es muestra de que Lucrecio despliega De rerum natura a partir del núcleo duro, riguroso y sistemático de la doctrina de Epicuro. Y sin embargo, si bien es cierto que describe y desarrolla los fundamentos del

52 Ibid., libro I, 45-49.

53 Ibid., libro v, 91-234.

${ }^{54}$ Ibid., libro III, 31-93. En diversos momentos del poema, Lucrecio insiste en que lo que permite vencer los temores y supersticiones de los seres humanos es la contemplación y el conocimiento de la naturaleza, lo cual nos abre el camino para alcanzar la tranquilidad del alma. $C f$. Ibid., libro I, 146-148; libro II, 58-61; libro III, 91-93, y libro VI, 39-41.

55 Ibid., libro v, 509-770.

${ }^{56}$ Ibid., libro VI, 96-1 137.

${ }^{57}$ Ibid., libro II, 1-61.

${ }^{58}$ Ibid., libro I, 45-49.

${ }^{59}$ Ibid., libro III, 830-930.

${ }^{60}$ Ibid., libro III, 1 053-1 075.

${ }^{61}$ Ibid., libro III, 1 076-1 094.

${ }^{62}$ Ibid., libro IV, 1 058-1 287. 
pensamiento de su maestro, también lo es que Lucrecio no se limita a la mera traducción, del griego al latín, o a la repetición de sus postulados. De hecho, desde las primeras líneas, desde la enigmática invocación a Venus, se muestra su magistral escritura, que se extiende a lo largo de todo el poema:

Madre de los Enéadas, gozo de los hombres y dioses, alma Venus, que bajo los signos errantes del cielo animas al mar que lleva a las naves y a la tierra fecunda, por ti todo género viviente es concebido y nacido contempla las luces del sol; de ti, diosa, de ti huyen los vientos, de ti las nubes del cielo, y a tu llegada, para ti, la tierra artífice ofrece suaves flores, para ti sonríen las llanuras del mar y el cielo sereno brilla con la luz derramada. ${ }^{63}$

Y líneas después, Lucrecio añade su sorprendente súplica a la diosa:

puesto que sola gobiernas la naturaleza de las cosas y sin ti nada nace a las divinas regiones de la luz, ni nada alegre ni amable sucede, deseo que seas mi aliada al escribir los versos que intento componer sobre la naturaleza de las cosas. ${ }^{64}$

Y en efecto, se trata de una súplica que sorprende porque, a pesar del anhelo enunciado, Lucrecio tiene la clara conciencia epicúrea, que de inmediato afirma categóricamente, de acuerdo con la cual los dioses se encuentran a buen recaudo de nuestros asuntos, que en nada están necesitados de nosotros y que ni los favores los alcanzan ni la ira los toca. ${ }^{65}$ Incluso, asevera que, más que haber sido creada por inteligencia alguna, la totalidad que habitamos es resultado de múltiples choques entre los cuerpos primeros, los cuales finalmente se han agrupado en un orden tal, que

hace que los ríos con las abundantes aguas de su corriente abastezcan al ávido mar y la tierra renueve sus frutos abrigada por el calor del sol, florezca la especie de los seres vivos y vivan los fuegos errantes del éter. ${ }^{66}$

${ }^{63}$ Ibid., libro I, 1-9. La versión castellana de los fragmentos citados del poema es mía.

${ }^{64}$ Ibid., libro I, 21-25.

${ }^{65}$ Ibid., libro I, 44-49.

${ }^{6}$ Ibid., libro I, 1 031-1 034. 
Así, observador por doctrina de la naturaleza de las cosas, Lucrecio describe el movimiento de los cuerpos en el todo, en particular el de los seres vivos, la manera en que se forman y engendran, se alimentan y viven, y tiempo después retornan a la tierra o al éter inmenso:

En fin, todos somos oriundos de semilla celeste, para todos es el mismo padre de quien, cuando la generosa madre tierra ha recibido gotas de líquido humor, preñada pare nítidos cereales, abundantes árboles y a la especie humana, pare todas las especies de fieras, procura alimentos con los que todos nutren sus cuerpos y pasan una vida dulce y propagan su prole; por lo que merecidamente ha obtenido el nombre de madre. Retorna así de vuelta lo que antes fue de la tierra a la tierra y lo enviado desde las orillas del éter lo recuperan de nuevo, devuelto, las regiones del cielo... ${ }^{67}$

Y acaso desde la contemplación del movimiento perpetuo, desde el examen de ida y vuelta de los seres a la tierra o al éter, que es también movimiento de vida y muerte, es que emergen los afanes y temores de los seres humanos, su dolor y sus tinieblas, al barruntar que su propia vida habrá de dar paso a la muerte. Aunque para Lucrecio, fiel a su mentor, lo insensato es precisamente huir de lo que nos es propio, correr precipitados queriendo evitarlo, cambiar de lugar de manera incesante, en vez de consagrarnos al conocimiento de la naturaleza de las cosas que, en su muda perpetua, nos muestra que:

Hay en efecto un límite de la vida seguro para los mortales y no se puede evitar que a la muerte vayamos. ${ }^{68}$

Quizá por ello, Lucrecio afirma que es suave mirar a distancia los esfuerzos de quien lucha por evitar un naufragio, no porque el sufrimiento de otro genere placer, sino porque es suave contemplar de lejos los males de los que carecemos. Aunque además, sugiere,

nada es mas suave que ocupar los elevados templos bien guarnecidos edificados por la enseñanza de los sabios, desde donde puedas mirar a los otros y por todos lados verlos vagar y buscar errantes el camino de la vida,

${ }^{67}$ Ibid., libro II, 991-1 001.

${ }^{68}$ Ibid., libro III, 1 078-1 079. 
competir en talento, rivalizar en nobleza, esforzarse noches y días con intensa fatiga por elevarse al más grande poder y apoderarse de las cosas... ${ }^{69}$

Es decir, como para Epicuro, para Lucrecio no hay placer superior a que "la mente disfrute de una agradable sensación alejada de preocupación y miedo"; ${ }^{70}$ no hay mayor bien que disfrutar de la tranquilidad del alma producida por la práctica de la filosofía. Es situados en los elevados templos edificados por la enseñanza de los sabios, que a distancia podemos mirar los afanes inútiles de quienes se empeñan en alcanzar la opulencia y el poder y, más que ocuparse de sí mismos, se esfuerzan por competir e imponerse a los otros. Es desde la filosofía que podemos volver hacia nosotros y dominar incluso las inclinaciones propias del temperamento del que la naturaleza nos dotó y llevar una vida que se asemeje a la imperturbable de los dioses. ${ }^{71}$ Es desde la filosofía que, con mente serena, ${ }^{72}$ podemos gobernar el transcurrir de nuestra vida $y$ acceder a los supremos deleites de la existencia. ${ }^{73}$ Es con la filosofía, que es contemplación y conocimiento de la naturaleza, que aprendemos que la muerte es nada para nosotros, ${ }^{74}$ y que podemos alejarnos de las narraciones que nos mantienen inquietos y temerosos del castigo de los dioses, de un supuesto tormento eterno después de la muerte:

Si tienes esto bien sabido, se ve que la naturaleza, libre siempre, privada de amos soberbios,

todo lo hace, por su propia voluntad, sin la competencia de los dioses.

Pues, por los sagrados corazones de los dioses que en paz tranquila pasan su vida plácida y serenamente,

¿quién puede regir la suma de lo inmenso, quién tener en su mano

el control de las riendas impetuosas de lo profundo,

quién a la vez hacer girar todos los cielos

y calentar todas las tierras feraces con fuegos etéreos,

o en todos los lugares estar presente en todo tiempo

para hacer con nubes tinieblas y lo sereno del cielo

sacudir de improviso, arrojar luego rayos

y destruir a menudo sus propios templos y retirándose a desiertos

${ }^{69}$ Ibid., libro II, 7-13.

${ }^{70}$ Ibid., libro II, 18-19.

${ }^{71}$ Ibid., libro III, 307-321.

${ }^{72}$ Ibid., libro v, 1 117-1 119.

${ }^{73}$ Ibid., libro v, $1430-1433$.

${ }^{74}$ Ibid., libro III, 830. 
enfurecerse y ensayar su venablo, que a menudo a culpables pasa por alto y quita la vida a inocentes y a quienes no lo merecen? ${ }^{75}$

De manera que, para Lucrecio, la contemplación nos muestra que la naturaleza, libre de los que llama "amos soberbios", por sí misma todo lo rige sin que medie divinidad alguna; porque, quién, pregunta, puede regir al todo en su inmensidad. Así, en vez de mitos que invocan a los dioses, que nos atemorizan con castigos y tormentos eternos, Lucrecio anuncia lo que llama "una nueva verdad", a cuya contemplación invita:

Ahora dirige tu ánimo a una razón verdadera.

Pues una realidad extraordinaria y nueva se dispone a llegar a tus oídos y una nueva visión de las cosas a mostrársete.

Aunque ninguna cosa es tan fácil que no sea, al principio, más difícil de creer, ni de la misma manera nada tan grande ni tan maravilloso que no vayan todos paulatinamente dejando de admirarla. En principio, el claro y puro color del cielo y lo que en sí contiene, astros errantes por todas partes y la luna y la clara luz del esplendor del sol; si ahora todas estas cosas existiesen por primera vez para los mortales, si de improviso les fuesen ahora súbitamente mostradas, ¿qué más admirable pudiera decirse que estas cosas o que antes se atrevieran las gentes a creer que existe?

Nada según creo: hasta tal punto esta visión habría de ser admirable. ${ }^{76}$

Al inicio de su carta a Heródoto, Epicuro, decíamos arriba, presenta dos principios esenciales de su pensamiento. Es necesario, dice a su discípulo, expresar con claridad el significado de las palabras, lo que, a su vez, permite la emisión de juicios precisos; apunta además que es indispensable para la formulación de la teoría de la naturaleza, estar atentos a las sensaciones, percepciones y sentimientos que experimentamos. Ahora bien, en el desarrollo de De rerum natura a partir del núcleo del pensamiento epicúreo, Lucrecio sigue de cerca ambos principios. Con respecto al primero, es tal su cuidado, que en diversos fragmentos nos deja conocer las dificultades de formular en el

75 Ibid., libro II, 1 090-1 104.

${ }^{76}$ Ibid., libro II, 1 023-1 037. 
latín de su tiempo, con términos apropiados, el pensamiento de su maestro. Dice Lucrecio a Memio, al amigo a quien dedica su poema:

Y no se oculta de mi ánimo que los oscuros hallazgos de los griegos son difíciles de ilustrar en versos latinos, sobre todo cuando deben tratarse muchas cosas con nuevas palabras, a causa de la pobreza de la lengua y la novedad de las cosas; sin embargo, tu virtud y el suave gozo esperado de tu amistad, me invita a soportar cualquier trabajo y me inducen a velar en las noches serenas, buscando con qué palabras y con qué canto, en fin, pueda abrir a tu mente las claras luces para que puedas examinar a fondo las cosas ocultas. ${ }^{77}$

Aunque además de referir sus escrúpulos en torno al cuidado de las palabras, Lucrecio sigue de cerca el segundo principio. De hecho, no sólo lo sigue sino lo desarrolla de una manera tal, que no cabría esperarse de la mera lectura de los textos conservados de Epicuro. En efecto, a lo largo del poema asistimos a una minuciosa descripción de diversas sensaciones, percepciones y sentimientos que, de acuerdo con nuestra naturaleza, experimentamos. Así, en tanto que la sensibilidad es la base de la teoría de la naturaleza epicúrea, Lucrecio se detiene en cada uno de los sentidos, a los que presenta, no sólo en su funcionamiento regular, sino también a partir de los errores que solemos cometer en su utilización; errores que provienen, afirma como Epicuro, no de los sentidos sino de la mente, con la que interpretamos erróneamente diversas sensaciones. ${ }^{78}$ En otros momentos, Lucrecio alude a diversos sentimientos que experimentamos. Por ejemplo, los propios de la pasión amorosa, a la que describe deliciosamente, ${ }^{79}$ aunque también los que caracterizan a la inquietud que, ante la ineludible muerte, surgen en el alma:

Si los hombres pudiesen, al igual que parecen sentir el peso que habita en su ánimo y los fatiga con su carga, conocer también las causas por las que ello sucede y de dónde proviene la gran mole que se forma en el pecho, no llevarían así la vida, como ahora vemos a menudo, desconocer qué quiere cada uno para sí y buscar siempre cambiar de lugar, como si se pudiera deponer la carga. ${ }^{80}$

77 Ibid., libro I, 136-145.

${ }^{78}$ Ibid., libro IV, 216-823.

79 Ibid., libro IV, 1 037-1 287.

${ }^{80}$ Ibid., libro III, 1 053-1 059. 
A lo que líneas después, añade:

De este modo huye cada uno de sí y de quien, sin duda, no es posible escapar y a disgusto está adherido y a quien odia, porque enfermo no comprende la causa de la enfermedad; que si la viese bien, cada uno, dejando atrás sus asuntos, primero se dedicaría con afán a conocer la naturaleza de las cosas, ya que está en litigo el tiempo eterno, no una sola hora, en el que los mortales habrán de permanecer todo el tiempo que queda después de la muerte. ${ }^{81}$

Ahora bien, es claro que descripciones como las que acabo de citar, no aparecen, ni si quiera se barruntan, en los textos conservados de Epicuro. Si bien de acuerdo con el principio conforme al cual, para la práctica de la teoría de la naturaleza, cuya finalidad, ya lo sabemos, es alcanzar la tranquilidad del alma, es indispensable ocuparnos de las sensaciones, percepciones y sentimientos que experimentamos, es justo decir que, con sus minuciosos dibujos, a veces estampas, de lo que nos sucede, Lucrecio desarrolla y enriquece la filosofía de su maestro, al mostrarnos muchos de los obstáculos que habrá de enfrentar quien busca la tranquilidad del alma.

Aunque además, a lo que Lucrecio añade al pensamiento de Epicuro con sus imágenes, se suma lo que tenemos a la vista desde las primeras líneas del poema. Como mencionamos, Lucrecio escribe De rerum natura en hexámetros, esto es, en la misma forma en la que escribió Homero, con la cual, animado por una voluntad poética, emprende la tarea de hacer filosofía:

Y no se oculta a mi ánimo cuán oscuro es; pero con agudo tirso una gran esperanza de gloria ha herido mi corazón y a la vez me infundió en el pecho el suave amor de las Musas, por el que ahora inspirado recorro con vívida mente apartadas regiones de las Piérides no holladas antes por nadie: me deleita recoger flores nuevas y buscar una insigne corona para mi cabeza, de ahí de donde las Musas no hayan ceñido antes las sienes de nadie; primero, porque enseño acerca de grandes cosas y me empeño en liberar el ánimo de los nudos de las religiones; luego, porque de una cosa oscura compongo tan lúcidos cantos, tocándolo todo con la gracia de las Musas. ${ }^{82}$

\footnotetext{
${ }^{81}$ Ibid., libro III, 1 068-1 075.
}

${ }^{82}$ Ibid., libro I, 922-934. 
A su vez, a la voluntad poética que lo anima, hay que añadir lo que el propio Lucrecio dice líneas después a su amigo Memio, sobre el tono de la doctrina de la que su poema se ocupa:

así yo ahora, dado que esta doctrina a menudo parece ser demasiado amarga a quienes no la han tratado y el vulgo hacia atrás se aleja de ella con horror, he querido exponerte nuestra razón en el suave canto de las Piérides y como tocarlo con la dulce miel de las Musas, por si acaso podía retener de tal manera tu ánimo en mis versos, en tanto que con la mirada penetras toda la naturaleza de las cosas, con qué orden se encuentra dispuesta. ${ }^{83}$

Es decir, a la voluntad singular que lleva a Lucrecio a escribir poéticamente, hay que añadir un ingrediente más: la intención de quien quiere describir dulcemente la, al menos a veces, amarga naturaleza de las cosas, para su amigo Memio, es decir, para el otro, para los otros.

Si bien la presencia de cada uno de los principios contenidos en las cartas a Heródoto, Pitocles y Meneceo es muestra de que el poema se despliega a partir del pensamiento de Epicuro, en De rerum natura Lucrecio da un giro con respecto al pensamiento de su maestro. Es cierto, lo hemos querido mostrar, que Lucrecio sigue con fidelidad la doctrina epicúrea en la presentación del conjunto de la teoría de la naturaleza y en lo que constituye su finalidad: procurar una vía para alcanzar la tranquilidad del alma. A la vez, Lucrecio sigue a Epicuro también en los dos principios esenciales de su teoría: en todo momento busca ser preciso en cuanto al uso de las palabras y, a lo largo del poema, despliega sendas descripciones de sensaciones, percepciones y sentimientos a los que, para alcanzar la ataraxia, conviene atender en nosotros mismos. Incluso, como ya sugerimos, es posible afirmar que, en esto último, De rerum natura desarrolla, enriquece el cuerpo del pensamiento de Epicuro, en tanto que muestra la distancia que hay que salvar y los obstáculos que enfrentar, en el camino hacia la tranquilidad del alma. Pero si bien el dibujo de lo que hay que superar es fundamental, no constituye aún el giro que De rerum natura da con respecto a la filosofía de Epicuro.

${ }^{83}$ Ibid., libro I, 943-950. 
El giro al que me refiero comienza a insinuarse en la voluntad poética de Lucrecio, aunque, en principio, pareciera ser sólo manifestación de un deseo personal. Dice el poeta, recordemos:

me deleita recoger flores nuevas

y buscar una insigne corona para mi cabeza, de ahí

de donde las Musas no hayan ceñido antes las sienes de nadie...

Pero además, a lo que parece ser aspiración personal, hay que sumar el tono con el que se dirige a Memio y, con ello, al otro, a los otros: con su poema, Lucrecio busca atenuar, con la miel de las musas, lo amargo de la teoría de la naturaleza. Y sin embargo, ambos momentos, el de la voluntad individual y el volverse hacia el otro, sólo preparan el giro fundamental, consistente en que poema está escrito en hexámetros, es decir, en forma poética, lo cual trastoca la expresión del pensamiento de Epicuro, dándole un nuevo aliento.

No se trata sólo de una cuestión de estilo. El giro consiste en que, al expresar en forma poética uno de los pensamientos más sólidos y rigurosos que haya dado a luz Occidente, Lucrecio nos entrega, con él, una mirada poética hacia la naturaleza. Es decir, a lo largo de los seis libros de De rerum natura, Lucrecio nos entrega la multiplicidad del todo expresada poéticamente: los astros y los átomos, el tiempo y el vacío, los mares y los montes, la lluvia y la nieve, el Sol y la Luna, el trueno y el rayo, el alma y la muerte, tienen lugar, brotan poéticamente en la forma y la belleza en las que son descritos. A lo largo de su prodigioso poema, Lucrecio nos conduce a través de una naturaleza que en sí misma es poética, a la vez que nos invita a habitarla poéticamente y a tener presente que su contemplación es un ejercicio de la filosofía que busca alcanzar la tranquilidad del alma. Un ejercicio poético de la filosofía que, al tiempo de mostrarnos la visión admirable del todo y de sus partes, busca hacernos capaces de enfrentar con jovialidad el azar de la naturaleza, aunque también el temor, las tinieblas y las supersticiones, las amenazas de la religión, la muerte misma. Así, con De rerum natura, Lucrecio abre una posibilidad para nuestra existencia en la que pensamiento y forma, tranquilidad del alma y expresión poética, filosofía y poesía, se funden en una unidad indisoluble. 